\title{
A study on relapse prevention in cases of alcohol dependence syndrome
}

\author{
Amitabh Saha \\ Department of Psychiatry, Srinagar, Jammu \& Kashmir, India \\ Email address \\ sahaing@gmail.com
}

\section{To cite this article:}

Amitabh Saha. A Study on Relapse Prevention in Cases of Alcohol Dependence Syndrome. American Journal of Life Sciences. Vol. 1, No. 4, 2013, pp. 184-188. doi: 10.11648/j.ajls.20130104.17

\begin{abstract}
Background- There have been few studies on relapse preventive strategies on people with alcohol dependence syndromes. There have been various factors for causes of relapse even after undergoing detoxification and other therapeutic measures. The use of anticraving medications and psychotherapy have been the common modalities used in the management of people dependent on alcohol.. Methods- 100 cases diagnosed with alcohol dependence syndrome were placed into two separate groups of fifty each. One group was placed on anticraving medication, Tab Acamprosate, and the other group was maintained on psychotherapy sessions. They were followed up at 0,6 and 12 month period. Scales were used to screen alcohol dependence (ADS, Brief MAST) and a scale specifically designed for the Indian people were used to assess stressful life events (AFMC Life Events Scale). Results- Relapse rates were ascertained at the given time of follow up. Analysis revealed that a total of 09 cases relapsed in this one year period. The relapse rates were higher in the first six months after therapy than in the later follow up period. 06 cases that relapsed were from psychotherapy group and the remaining 03cases were from the group receiving anticraving medications. But the difference between the two groups was not statistically significant. Various stressful events were highlighted using Marlatt's taxonomy for causes of relapse. Conclusions- Relapse rate was commoner in the initial months after undergoing detoxification therapy. Anticraving medication was in no way superior to a structured psychotherapy sessions in relapse prevention.
\end{abstract}

Keywords: Anticraving Medication, Psychotherapy, Stress, Acamprosate, Life Events, Relapse

\section{Introduction}

Relapses are very frequent in alcohol dependent patients. It is well known that Alcohol dependence syndrome is one of the commonest substance use disorder seen by Psychiatrists the world over. The consumption of alcohol and its abuse has been known to all societies in the world since many ages. Alcohol beverages were known to India since the Vedic and the post Vedic period (1). In addiction disorders it is very important to know that besides identifying an individual to be dependent on a particular psychoactive substance, the subsequent detoxification programme has to be followed up with a very good relapse prevention strategy. Advances in the identification of neurotransmittersystems involved in the addiction cycle have led to the developmentof new medications that, used in combination with counseling, further improve treatment outcome over that with counselingalone. Acamprosate is one of the medications that have shownsuccess in promoting abstinence in alcohol-dependent individuals (2).

\section{Review of Literature}

Integration of Acamprosate therapy into clinicalpractice has enhanced the chances to prevent relapse in alcoholics (3). Various studies in previous literature have revealed the successful outcomes of using anticraving medications in relapse prevention strategies for alcohol deaddiction therapy. In various deaddiction centers around the world, counseling sessions also involve the use of anticraving medications at a later stage to improve the outcome of therapy to prevent relapse in patients having alcohol dependence syndrome. People are diagnosed to be alcohol dependent by using the well-known ICD -10 or DSM-1V diagnostic criteria. In the use of psychotherapy and anticraving medications several results have been obtained. It is interesting to note that in the several multicentric studies carried out the world over their remains no statistical significant difference in the overall response rates when the anticraving medications was compared to 
Psychotherapy (4).

By relapse we mean that the individual starts consuming alcohol to the level wherein he requires therapy and meets the diagnostic criteria again. The relapse rates are found to be highest for alcoholics in the first year itself. In order to prevent relapse in alcoholics several US FDA approved anticraving medications have now become available for use Acamprosate Naltrexone werethe commonly used medications. Other medications like Tab Topiramate, Tab Baclofen and Cap Fluoxetine have also been used (5). In this study we intend to find out ways for prevention of relapse in alcohol dependence patients by comparing the patients by placing them in two groups.

One group received anticraving medicine i.e. Tab Acamprosate in therapeutic dose and the other group received psychotherapy in standardized format and regular sessions.

\section{Material and Methods}

The study was carried out in a tertiary care hospital. The study was conducted on the following: a) 100 consecutive patients admitted to the psychiatric center who were diagnosed to be having alcohol dependence syndrome (diagnosed as per ICD -10 Diagnostic criteria). b) These 100 patients were initially managed by detoxification strategies. c) They were randomly assigned into the two groups wherein one received anticraving medication i.e. Tab Acamprosate $(333 \mathrm{mg}$ ) in therapeutic doses. The other group was placed on psychotherapy sessions. d) The data were collected and studied over a one year period. They were studied at 0,6 and 12 month intervals. The patients were regularly followed up in the outpatient department every month. A comprehensive examination, data collection, and observation for evidence of relapse was done at 06 monthly intervals wherein the scales were administered and clinical, hematological and biochemical parameters were assessed. Tests like MCV. GGT, LFT were done. Ultrasonographic findings of abdomen were done and the individual's unit report for his alcohol use was studied. Purposive sampling was done as only diagnosed patients who met the ICD -10 diagnostic criteria for alcohol dependence syndrome were only taken.

\section{Scales}

1) AFMC (Armed Forces Medical College) Life Events scale was used for evaluation of any life stressors. The A.F.M.C. Life events scale was a 52 items scale constructed with validity and sensitivity. (6).

2) For assessing alcohol dependence the ADS (Alcohol dependence Scale) was applied.

3) Brief MAST (Brief Michigan Alcohol Screening Test)- It had 10 questions to be answered in a yes/no format. The score range was 0-29 (7).

4) For the collection of demographic data a questionnaire was prepared which was administered to all patients and controls.

At follow up: The individuals was followed up at 0,6 and 12 months and were evaluated by a detailed history taking Performa, hematological and biochemical tests, administration of above mentioned scales, review of unit report with due emphasis being laid on his alcohol status. History for compliance with medications was taken for group placed on anticraving medications. The other group would be subjected to booster psychotherapy session at this time.

\section{Results}

In the present study, one hundred cases were taken and data collected pertaining to the study. They were then compared with each other. Each group consisted of 50 cases which were purposively sampled. A total of 09 cases relapsed overall in both the groups over a period of one year follow up. The relapse rates were higher in the first 06 months than in the following 06 months. The number of cases which relapsed was more in the group which had received psychotherapy sessions (Total- 06) as compared to the group which had been placed on medications (Total-03) as seen in table 1 .

Table 1. The number of cases that relapsed in the group

\begin{tabular}{lll}
\hline $\begin{array}{l}\text { Number of relapsed } \\
\text { cases }\end{array}$ & $\begin{array}{l}\text { Medication } \\
\text { group }\end{array}$ & $\begin{array}{l}\text { Psychotherapy } \\
\text { group }\end{array}$ \\
\hline In first 06 months & $\mathrm{N}=02$ & $\mathrm{~N}=04$ \\
& $\mathrm{~N}=01$ & $\mathrm{~N}=02$ \\
\hline
\end{tabular}

$\mathrm{df}=1$ Chi square- $0.01 \mathrm{p}>0.05$ (NS) $(\mathrm{p}$ value-1.00)

There was no significant statistical difference between the two groups for the number of cases that relapsed in the first 06 months of follow up in the study as seen in table 2 .

Table 2. Studying the comparison of cases that relapsed in the group in the first 06 months

\begin{tabular}{lll}
\hline $\begin{array}{l}\text { Study of cases in first 06 } \\
\text { months }\end{array}$ & $\begin{array}{l}\text { Medication } \\
\text { group }\end{array}$ & $\begin{array}{l}\text { Psychotherapy } \\
\text { group }\end{array}$ \\
\hline Number that relapsed & $\mathrm{N}=02$ & $\mathrm{~N}=04$ \\
Cases that did not relapse & $\mathrm{N}=48$ & $\mathrm{~N}=46$ \\
\hline
\end{tabular}

$\mathrm{df}=1$ Chi square- $0.71 \mathrm{p}>0.05(\mathrm{NS})(\mathrm{p}$ value- 0.399$)$

There was no significant statistical difference between the two groups for the number of cases that relapsed in the following 06 months of follow up in the study as seen in table 3 . 
Table 3. Studying the comparison of cases that relapsed in the following 06 months.

\begin{tabular}{lll}
\hline $\begin{array}{l}\text { Study of cases in } \\
\text { following 06 months }\end{array}$ & $\begin{array}{l}\text { Medication } \\
\text { group }\end{array}$ & $\begin{array}{l}\text { Psychotherapy } \\
\text { group }\end{array}$ \\
\hline Number that relapsed & $\mathrm{N}=01$ & $\mathrm{~N}=02$ \\
Cases that did not relapse & $\mathrm{N}=49$ & $\mathrm{~N}=48$ \\
\hline
\end{tabular}

$\mathrm{df}=1$ Chi square- $0.34 \mathrm{p}>0.05(\mathrm{NS})(\mathrm{p}$ value- 0.557$)$

When the Brief MAST scores were compared their was no significant statistical difference between the two groups. Scores of less than 5 was predominantly scored in both groups as seen in table 4 .

Table 4. The Brief MAST score after 06 months of follow up

\begin{tabular}{lll}
\hline Brief Mast Score & $\begin{array}{l}\text { Medication group } \\
(\mathbf{N}-50)\end{array}$ & $\begin{array}{l}\text { Psychotherapy } \\
\text { group(N-50) }\end{array}$ \\
\hline More than 17 & $\mathrm{N}=01$ & $\mathrm{~N}=02$ \\
Between 6and 16 & $\mathrm{N}=01$ & $\mathrm{~N}=02$ \\
Less than 5 & $\mathrm{N}=48$ & $\mathrm{~N}=46$ \\
\hline
\end{tabular}

$\mathrm{df}=2$ Chi square- $0.71 \mathrm{p}>0.05(\mathrm{NS})(\mathrm{p}$ value $=0.70)$

The Brief MAST scores at the end of 12 months also revealed that there was no significant statistical difference between the two groups. Scores of less than 5 was predominantly scored in both groups as seen in table 5 .

Table 5. The Brief MAST score at the end of 12 months of follow up

\begin{tabular}{lll}
\hline Brief Mast Score & $\begin{array}{l}\text { Medication group } \\
(\mathbf{N}-50)\end{array}$ & $\begin{array}{l}\text { Psychotherapy } \\
\text { group(N-50) }\end{array}$ \\
\hline More than 17 & $\mathrm{~N}=01$ & $\mathrm{~N}=01$ \\
Between 6and 16 & $\mathrm{N}=00$ & $\mathrm{~N}=01$ \\
\hline
\end{tabular}

$\mathrm{df}=2$ Chi square- $1.01 \mathrm{p}>0.05$ (NS) $\mathrm{p}$ value $=0.60$

When the ADS scores were compared there was no significant statistical difference between the two groups. Scores of less than 13 was predominantly scored in both groups as seen in table 6 .

Table 6. The ADS score after 06 months of follow up

\begin{tabular}{lll}
\hline ADS SCORE & $\begin{array}{l}\text { Medication } \\
\text { group }(\mathbf{N}-50)\end{array}$ & $\begin{array}{l}\text { Psychotherapy } \\
\text { group(N-50) }\end{array}$ \\
\hline Between 1 and 13 & $\mathrm{N}=48$ & $\mathrm{~N}=46$ \\
Between 14 and 47 & $\mathrm{N}=02$ & $\mathrm{~N}=04$ \\
\hline
\end{tabular}

$\mathrm{df}=1$ Chi square- $0.71 \mathrm{p}>0.05(\mathrm{NS}) \mathrm{p}$ value $=0.39$
When the ADS scores were compared at the end of 12 months their was no significant statistical difference between the two groups. Scores of less than 5 was predominantly scored in both groups as seen in table 7 .

Table 7. The ADS score at the end of 12 months of follow up.

\begin{tabular}{lll}
\hline ADS SCORE & $\begin{array}{l}\text { Medication } \\
\text { group (N-50) }\end{array}$ & $\begin{array}{l}\text { Psychotherapy } \\
\text { group(N-50) }\end{array}$ \\
\hline Between 1and 13 & $\mathrm{N}=49$ & $\mathrm{~N}=48$ \\
Between 14 and 47 & $\mathrm{N}=01$ & $\mathrm{~N}=02$ \\
\hline
\end{tabular}

$\mathrm{df}=1$ Chi square- $0.34 \mathrm{p}>0.05(\mathrm{NS}) \mathrm{p}$ value $=0.55$

Table 8. The causes of relapse in both study groups encompassing stressors like domestic stressors, financial stressors and occupational stressors in total

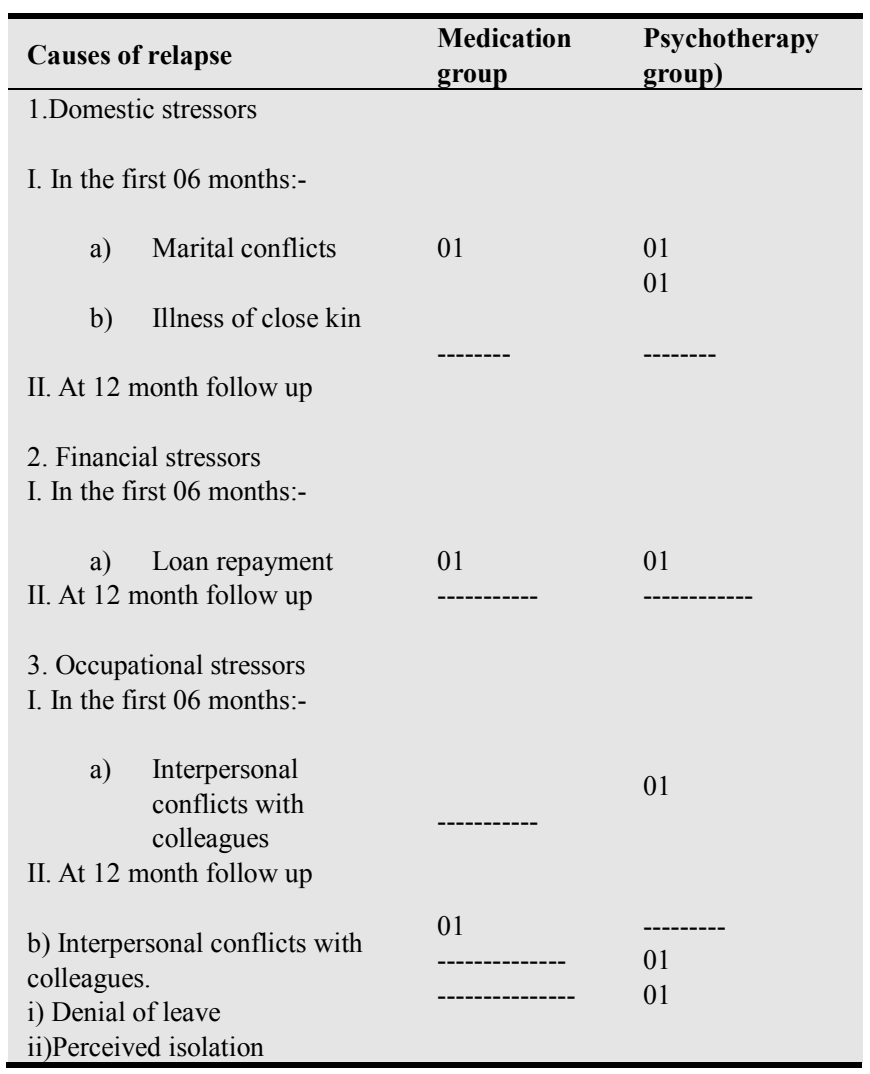

AFMC Life events scale was used. Occupational stressors were noted to be present in the majority of patients in comparison to other causes of stressors that a person is exposed to. These stressors were further analyzed in detail and the following results were obtained when both the groups were studied and compared. Domestic stressor was noted in total of 03 cases that had relapsed out of which the following was observed:-

a) One case in the medication group cited poor marital relationship with spouse.

b) In the group which had received psychotherapy alone one individual cited poor marital relationship 
with spouse and the other cited a prolong illness of his only son. The above findings were noted in the first 06 months of follow up.

Financial stressor was noted in both groups. One case each in the medication group and psychotherapy group had taken loan for which he had to pay his monthly interest dues and he felt to be under heavy pressure. This was noted in the relapse cases at 06 month follow up. At the 12 month follow up no relapse noted citing any financial causes.

The occupational stress cited and clearly elucidated by the cases included the following results:-

a) Interpersonal conflict noted among colleagues in one case of the psychotherapy group in the first 06 month follow up period. None reported in the medication group.

b) At the time of 12 month follow up one case in medication group cited stress due to interpersonal conflict among colleagues. Two cases were noted in psychotherapy group for denial of leave and perceived isolation in the work place respectively. In the finding we observed that there was no significant difference between the two groups for the various stressful conditions that had been studied.

\section{Discussion}

It was interesting to note that the majority of these relapse rates were more in the first 06 months after therapy The relapse rates when calculated came out to be $9 \%$ overall in the study as in table 1 . Almost $6 \%$ relapsed in the first 06 months when compared to relapse rates of $3 \%$ in the next 06 months of follow up. In the initial 06 months of follow up, $2 \%$ of the medication group and $4 \%$ of the group receiving psychotherapy had relapsed as seen in table 2. In the next 06 months i.e. at end of 12 months follow up $3 \%$ in total had relapsed. In this $1 \%$ of the medication group and $2 \%$ of the patients in the psychotherapy group had shown features of relapse as seen in table 3 . The Brief MAST scores when compared between the two groups as noted in table 4 \& 5 were not statistically significant. Similar were the findings on the ADS score for the two groups as seen in tables $6 \& 7$. The cases had been followed up to study the number of relapses they had in this one year period. In table 8 , the various stressors were studied. According to Marlatt's taxonomy (8) the reasons for relapse could fall under immediate determinants. The domestic disputes and problems with peer groups falling under the rubric of "interpersonal conflicts" and the inability to pay the loan or looking after an ailing son led to negative emotional states such as frustration, anger and anxiety, the so called "intrapersonal conflict".

When they were followed up in the next 06 months and evaluated at the 12 th month, 01 case in the medication group and 02 cases in the psychotherapy group had relapsed. As per detailed history taken from the cases, the ones from the medication group cited interpersonal conflict with his seniors and felt that he was being unfairly treated. In the psychotherapy group one case cited denial of leave on several occasions when it mattered the most (intrapersonal conflicts leading to anger, frustration) and the other perceiving to be isolated in the work place after being present there for last one year. He complained of lack of friends or a peer group with whom he could share his worries. He was married but his wife was staying in a remote village. In both these cases the individuals took to relief drinking, probably resulting in the relapse. All the above finding is in accordance to the causes of relapse as given in Marlatt's taxonomy. The high risk situations as given under immediate determinants were the common causes for relapse in this study. No social pressure which included direct verbal or nonverbal persuasion by colleagues or positive emotional states e.g. celebration or exposure to alcohol related cues were seen in the study (9, 10). The study was done keeping in mind the regularity in follow up of these cases and the assessment of these cases were also done at monthly intervals to be aware of their status. There was no case that was lost to follow up and the units were helpful in providing detailed information on the individual as seen by the submitted unit reports in all the 100 cases which were under study.

\section{Conclusions}

The final aim and conclusion was to study relapse prevention in alcoholics by comparing use of an anticraving drug like Acamprosate with cases that had received psychotherapy. At the end of the study we could conclude that there was no significant difference in relapse prevention in either of these two interventions i.e., anticraving drugs against psychotherapy sessions; which makes us to infer that none is more superior than the other.

\section{Limitations of the Study}

The sample size of the study was 100 cases which probably is small and can be one of the limitations of this study. In order to have a very substantive result, a similar study could be required using far more strength of sample size in terms of cases studied.

\section{Scope for Further Research}

In such studies it would be reasonable to study the efficacy of structured psychotherapy sessions against a placebo group. In the similar way the efficacy of an anticraving medication may be tested in prevention of relapse in patients with alcohol dependence syndrome by comparing it to a sample group exposed to placebo alone. Further research may be done by comparing the efficacy in between various groups of anticraving medications known in prevention of alcohol relapse e.g. Naltrexone, baclofen etc. 


\section{Intellectual Contribution of Author}

Study Concept: Dr Amitabh Saha, MD Psychiatry

\section{References}

[1] Allchin FR. India: The home of distillation? Man 1979; 14: 55-63.

[2] Tempesta, E., Janiri, L., Bignamini, A., Chabac, S. and Potgieter, A. (2000) Acamprosate and relapse prevention in the treatment of alcohol dependence: Alcohol \&Alcoholism35, 202-209.

[3] Poldrugo F. (1997) Acamprosate treatment in a long-term community based alcohol rehabilitation programme. Addiction 92, 1537-1546.

[4] Soyka, M., Preuss, U. and Schuetz, C. (2002) Use of acamprosate and different kinds of psychosocial support in relapse prevention of alcoholism. Results from a non-blind, multicenter study. Drugs $R \& D$ 3, 1-12.

[5] Volpicelli JR, Pettinati HM, McLellan AT, O’Brien CP (eds):
Combining Medication and Psychosocial Treatments for Addiction-The Brenda Approach. New York, Guilford, 2001

[6] MSVK Raju, Chaudhary S, K Srivastava, S K Salujha. Quantification of stressful life events in service personnel. Indian Journal of Psychiatry, 2001, 43(3):213-218.

[7] Singh G. Epidemiology of Alcohol use in India. Use of MAST, bMAST, AUDIT In: Ray R, Pickers RW (editors). Proceedings of the Indo-US Symposium on Alcohol and Drug Abuse. NIMHANS Publication No. 20. 1989; 3-11.

[8] Sadava, S.W., \& Pak A.W. Stress-related problem drinking and alcohol problems: A longitudinal study and extension of Marlatt's model. Canadian Journal of Behavioral Science 1993, 25(3): 446-464.

[9] Pohorecky, L.A. Stress and alcohol interaction: An update of human research. Alcoholism: Clinical and Experimental Research 1991;15(3): 438-459,

[10] Brown, S.A.; Vik, P.W.; Patterson, T.L.; Grant, I.; \& Schuckit, M.A. Stress, vulnerability, and adult alcohol relapse. Journal of Studies on Alcohol 1995. 56(5): 538-545. 